\title{
Occurrence of Subharmonic Tones in a Beam Supported Elastically
}

\author{
Mitsuhiro KATO*2 \\ ${ }^{* 2}$ Department of Mechanical Engineering, Faculty of Engineering, Mie University, \\ 1577 Kurimamachiya-cho, Tsu-shi, Mie, 514-8507 Japan
}

\begin{abstract}
The occurrence of subharmonic tones in a beam supported by springs and dampers at both ends, and subjected to a nonsymmetric excitation having two components, one independent of, and the other harmonically varying with, time is considered. The beam can form a system with internal resonance due to the size of spring constants of support ends. To analyze the problem, the method of multiple scales is used. The analysis shows that in the system with internal resonance considered here, subharmonic tones of orders $1 / 2$ and $1 / 3$ can occur in a multi mode. The validity of the theoretical analysis is confirmed by numerical simulation.
\end{abstract}

Key Words: Forced Vibration, Nonlinear Vibration, Vibration of Continuous System, Beam, Subharmonic Tone, Resonance Condition

\section{1. ま え がき}

はりが大振幅で振動するときの非線形たわみ振動の 問題は多くの研究者によって取扱われ，種々の振動の 発生の可能性が論ぜられてきている．著者もこの種の 問題の一つとして結合調波振動の問題を扱い, 複数の 調和外力を受けるはりが多モード形共振となり得るこ とを示した(1).

はりの支持には通常単純支持, 剛体支持あるいは片 持はりとして解析するのが一般的であり, 弾性支持, 粘弾性支持として解析する例は少ない. しかし実際の 外力の形態によっては, 支持を弾性支持とする必要の あるものは少なくない. はりの非線形たわみ振動を取 扱う場合, この種の場合に発生する振動の特性を把握 しておくことは重要であると思われる。しかしながら 弾性支持のうち横方向の弾性支持はりの問題は文献 (2) に見られるに過ぎない.

この報告では, 両端が減衰を有する集中ばねで支持 されたはりの非線形たわみ振動の問題を取り上げる. 支持をばね支持とすることにより，両端ばねのばね定

* 原稿受付 2008 年 4 月 8 日.

*1 正員, 三重大学工学部 (恶 514-8507 津市栗真町屋町 1577).

E-mail : kato@ss.mach.mie-u.ac.jp
数の大きさによって, 系は内部共振系となり, 系特有 の強制振動現象が生じる可能性がある。このような場 合の非線形振動現象の一例として分数調波振動を考察 の対象として取り扱う。両端単純支持はりの分数調波 振動の問題は $\mathrm{Nayfeh}^{(3)}$, 安田等(4)(5)により検討され た.ここでは調和外力のほかに時間に依存しない外力 が作用する両端弾性支持はりの分数調波振動の問題を マルチスケールの摂動法を用いて近似理論解析をす る. 解析により, 発生する分数調波振動を理論的に検 討してその振動特性, 安定性などを明らかにする.

次に理論で予想された振動の発生を数值シミュレー ションによって検証する.

\section{2. 基 礎 方程 式}

長さ $l$, 断面積 $A$ のはりを考える. はりの一方の端 を原点 $\mathrm{O}$ にとり, 平衡位置のはりに沿って $x$ 軸を， $x$ 軸と直角に $y$ 軸を定める. $y$ 軸方向の外力 $q$ によっ てはりに $y$ 軸方向にたわみ $w$ が生じるものとする. $q, w$ はいずれも時間 $t$ と座標 $x$ の関数である. 両端 はばねと減衰器で支持されており, はりの境界は軸方 向に移動しないものとする。またはりには粘性減衰が 作用するものとすると, 大たわみに対するはりの運動 方程式は 


$$
\begin{aligned}
& \rho A \frac{\partial^{2} w}{\partial t^{2}}+E I \frac{\partial^{4} w}{\partial x^{4}}-\frac{E A \partial^{2} w}{2 l \partial x^{2}} \int_{0}^{l}\left(\frac{\partial w}{\partial x}\right)^{2} \mathrm{~d} x \\
& \quad+C \frac{\partial w}{\partial t}+C_{0} \frac{\partial w}{\partial t} \delta(x-0)+C_{1} \frac{\partial w}{\partial t} \delta(x-l)=q
\end{aligned}
$$

となる。ここに $\rho, E, A, I, C$ はそれぞれはりの密度, 縦弹性係数, 断面積, 断面二次モーメント, 粘性減衰 係数であり, $C_{0}, C_{1}$ は左右端の減衰器の粘性減衰係数 である. $\delta$ はディラックのデル夕関数である.

はりの左右端はそれぞればね定数 $k_{0}, k_{1}$ のばねで支 持されているものとすると, 境界条件は

$$
\begin{aligned}
& x=0 \text { において } \frac{\partial^{2} w}{\partial x^{2}}=0, \quad E I \frac{\partial^{3} w}{\partial x^{3}}=-k_{0} w \\
& x=l \text { において } \frac{\partial^{2} w}{\partial x^{2}}=0, \quad E I \frac{\partial^{3} w}{\partial x^{3}}=k_{1} w
\end{aligned}
$$

で与えられる。

ここでは式(1)，（2）を見てわかるように両端のば ね力および減衰力は, 後に述べる固有値問題を考慮し て, それぞれ境界条件式, 運動方程式に分離して適用 した.

外力 $q$ は, 時間に依存しない項と角振動数 $\Omega$ の調 和外力の和

$$
q=q_{c}(x)+q(x) \cos \Omega t
$$

で与えられるものとする.

以下の無次元量

$$
\begin{aligned}
& \bar{\beta}=\frac{A}{l^{2}}, \quad t^{\prime}=\sqrt{\frac{E I}{\rho A}} \frac{\pi^{2}}{l^{2}} t, \quad x^{\prime}=\frac{x}{l}, \quad w^{\prime}=\frac{l}{\sqrt{I}} w \\
& \bar{\zeta}=\frac{l^{2}}{2 \pi^{2} \sqrt{\rho A E I}} C, \quad \bar{\zeta}_{0}=\frac{l}{2 \pi^{2} \sqrt{\rho A E I}} C_{0} \\
& \overline{\zeta_{1}}=\frac{l}{2 \pi^{2} \sqrt{\rho A E I}} C_{1}, \quad q_{c}^{\prime}\left(x^{\prime}\right)=\frac{l^{5}}{E I \sqrt{I}} q_{c}(x) \\
& q^{\prime}\left(x^{\prime}\right)=\frac{l^{5}}{E I \sqrt{I}} q(x), \quad \Omega^{\prime}=\sqrt{\frac{\rho A}{E I}} \frac{l^{2}}{\pi^{2}} \Omega \\
& k_{0}^{\prime}=\frac{l^{3}}{E I} k_{0}, \quad k_{1}^{\prime}=\frac{l^{3}}{E I} k_{1} \cdots \cdots \cdots \cdots \cdots \cdots \cdots \cdots(4)
\end{aligned}
$$

を導入し,これらを式(1), (2)に代入し, 肩の記号 「'」を省略すると

$$
\begin{gathered}
\pi^{4} \frac{\partial^{2} w}{\partial t^{2}}+\frac{\partial^{4} w}{\partial x^{4}}-\frac{\bar{\beta}}{2} \frac{\partial^{2} w}{\partial x^{2}} \int_{0}^{1}\left(\frac{\partial w}{\partial x}\right)^{2} \mathrm{~d} x \\
+2 \bar{\zeta} \pi^{4} \frac{\partial w}{\partial t}+2 \bar{\zeta}_{0} \pi^{4} \frac{\partial w}{\partial t} \delta(x-0)
\end{gathered}
$$

$+2 \bar{\zeta}_{1} \pi^{4} \frac{\partial w}{\partial t} \delta(x-1)=q_{c}(x)+q(x) \cos \Omega t$

および

$$
\begin{aligned}
& x=0 \text { において } \frac{\partial^{2} w}{\partial x^{2}}=0, \quad \frac{\partial^{3} w}{\partial x^{3}}=-k_{0} w \\
& x=1 \text { において } \frac{\partial^{2} w}{\partial x^{2}}=0, \quad \frac{\partial^{3} w}{\partial x^{3}}=k_{1} w
\end{aligned}
$$

を得る。

式 (5)の解を

$$
w=\sum_{m=1}^{\infty} X_{m}(t) W_{m}(x)
$$

とおく.ここで $X_{m}(t)$ はたわみ $w へ の ~ m$ 次の振動 モードの寄与の程度をあらわすモード座標であり, $W_{m}(x)$ は式 $(6)$ の境界条件を満たす線形系の $m$ 次の 振動モード関数

$$
\begin{gathered}
W_{m}(x)=\cos \lambda_{m} x+E_{m} \sin \lambda_{m} x+\cosh \lambda_{m} x \\
+F_{m} \sinh \lambda_{m} x \quad(m=1,2, \cdots) \quad \cdots \cdots \cdots \cdots
\end{gathered}
$$

である.ここに

$$
\begin{aligned}
& E_{m}=\frac{2 k_{0} \sinh \lambda_{m}-\lambda_{m}^{3}\left(\cosh \lambda_{m}-\cos \lambda_{m}\right)}{\lambda_{m}^{3}\left(\sinh \lambda_{m}-\sin \lambda_{m}\right)} \\
& F_{m}=\frac{2 k_{0} \sin \lambda_{m}-\lambda_{m}^{3}\left(\cosh \lambda_{m}-\cos \lambda_{m}\right)}{\lambda_{m}^{3}\left(\sinh \lambda_{m}-\sin \lambda_{m}\right)}
\end{aligned}
$$$$
(m=1,2, \cdots) \cdots
$$

である、ただし式 $(8)$ ，（9)の $\lambda_{m}$ は対応する線形系 の振動数方程式

$$
\begin{aligned}
& 2 \lambda^{6}-2\left(k_{0}+k_{1}\right) \lambda^{3} \sin \lambda \cosh \lambda \\
& \quad+4 k_{0} k_{1} \sin \lambda \sinh \lambda \\
& +2\left(k_{0}+k_{1}\right) \lambda^{3} \cos \lambda \sinh \lambda \\
& \quad-2 \lambda^{6} \cos \lambda \cosh \lambda=0 \quad \cdots \cdots
\end{aligned}
$$

の根であり, 線形系の固有角振動数 $p_{m}$ は

$$
p_{m}=\frac{\lambda_{m}^{2}}{\pi^{2}} \quad(m=1,2, \cdots)
$$

で与えられる.式(8)を式(7)に代入し,さらに式 (7)を式(5)に代入し, 式(5)の両辺に $W_{n}(x)$ を掛 けて, 両辺を 0 から 1 まで積分する。このようにして ガラーキンの方法を適用し，モード関数の直交性

$$
\int_{0}^{1} W_{r}(x) W_{s}(x) \mathrm{d} x=0, \quad r \neq s
$$

を考慮するとモード方程式として

$$
\begin{aligned}
& \ddot{X}_{n}+p_{n}^{2} X_{n}-\frac{\bar{\beta}}{2 I_{n} \pi^{4}}\left(\sum_{p=1}^{\infty} a_{p} X_{p}^{2}+\sum_{q=1, q \neq r}^{\infty} \sum_{i=1, r \neq q}^{\infty} a_{q r} X_{q} X_{r}\right)\left(\sum_{s=1}^{\infty} c_{n s} X_{s}\right)+2 \bar{\zeta} \dot{X}_{n}+\frac{2}{I_{n}} \bar{\zeta}_{0} W_{n}(0) \sum_{m=1}^{\infty} W_{m}(0) \dot{X}_{m} \\
& +\frac{2}{I_{n}} \bar{\zeta}_{1} W_{n}(1) \sum_{m=1}^{\infty} W_{m}(1) \dot{X}_{m}=\bar{Q}_{c n}+\bar{Q}_{n} \cos \Omega t
\end{aligned}
$$

を得る。ここに記号「・」は時間 $t$ に関する徵分を表し

$a_{p}=\lambda_{p}^{2} \int_{0}^{1}\left(-\sin \lambda_{p} x+E_{p} \cos \lambda_{p} x+\sinh \lambda_{p}+F_{p} \cosh \lambda_{p} x\right)^{2} \mathrm{~d} x$ 


$$
\begin{aligned}
& a_{g r}=2 \lambda_{q} \lambda_{r} \int_{0}^{1}\left(-\sin \lambda_{p} x+E_{p} \cos \lambda_{p} x+\sinh \lambda_{p} x+F_{p} \cosh \lambda_{p} x\right)\left(-\sin \lambda_{r} x+E_{r} \cos \lambda_{r} x+\sinh \lambda_{r} x\right. \\
& \left.+F_{r} \cosh \lambda_{r} x\right) \mathrm{d} x \\
& c_{n s}=\lambda_{s}^{2} \int_{0}^{1}\left(\cos \lambda_{n} x+E_{n} \sin \lambda_{n} x+\cosh \lambda_{n} x+F_{n} \sinh \lambda_{n} x\right)\left(-\cos \lambda_{s} x-E_{s} \sin \lambda_{r} x+\cosh \lambda_{s} x\right. \\
& \left.+F_{s} \sinh \lambda_{s} x\right) \mathrm{d} x \\
& I_{n}=\int_{0}^{1} W_{n}(x)^{2} \mathrm{~d} x, \quad \bar{Q}_{n}=\frac{1}{I} \int_{0}^{1} q(x) W_{n}(x) \mathrm{d} x, \quad \bar{Q}_{c n}=\frac{1}{I} \int_{0}^{1} q_{c}(x) W_{n}(x) \mathrm{d} x
\end{aligned}
$$

である・

\section{3. 分 数 調 波 振 動}

$3 \cdot 1$ 理論解析 式(13)において, 外力の角振動数 $\Omega$ が, はりの固有角振動数 $p_{n}$ の一つである第 $j$ 次固有角振 動数 $p_{j}$ の整数 $l$ 倍に近づき

$\Omega \cong l p_{j}$

となる場合に発生が可能である $1 / l$ 次分数調波共振を取り扱う. 以下では式(15) と同時に, 第 $j$ 次固有角振動数 $p_{j}$ と第 $k$ 次固有角振動数 $p_{k}$ の間に内部共振の条件として

$$
l p_{j} \cong p_{k}
$$

が満たされる場合に発生する振動について近似理論解析を進める。式(15)，(16)より

$Q \cong p_{k}$

が成り立つことに注意する。

式(15)，(17)よりここでは第 $j, k$ 次モードに着目し, 式(13)において $n=j, k$ 以外の $X_{n}$ を無視できるものとす る. 式(13)を $n=j, k$ の場合について展開すると

$$
\begin{aligned}
& \ddot{X}_{j}+p_{j}^{2} X_{j}=\beta_{j j 3} X_{j}^{3}+\beta_{j j 2 k 1} X_{j}^{2} X_{k}+\beta_{j j 1 k 2} X_{k}^{2} X_{j}+\beta_{j k 3} X_{k}^{3}-2\left(\zeta+\zeta_{0 j j}+\zeta_{1 j j}\right) \dot{X}_{j}-2\left(\zeta_{0 j k}+\zeta_{1 j k}\right) \dot{X}_{k} \\
& +Q_{c j}+Q_{j} \cos \Omega t \\
& \ddot{X}_{k}+p_{k}^{2} X_{k}=\beta_{k k 3} X_{k}^{3}+\beta_{k k 2 j 1} X_{k}^{2} X_{j}+\beta_{k k 1 j 2} X_{j}^{2} X_{k}+\beta_{k j 3} X_{j}^{3}-2\left(\zeta+\zeta_{0 k k}+\zeta_{1 k k}\right) \dot{X}_{k}-2\left(\zeta_{0 k j}+\zeta_{1 k j}\right) \dot{X}_{j} \\
& +Q_{c k}+Q_{k} \cos \Omega t
\end{aligned}
$$

ここに

$$
\begin{aligned}
& \frac{a_{j} c_{j k}+2 a_{j k} c_{j j}}{2 I_{j} \pi^{4}} \bar{\beta}=\beta_{j j 2 k 1}, \quad \frac{a_{k} c_{j j}+2 a_{j k} c_{j k}}{2 I_{j} \pi^{4}} \bar{\beta}=\beta_{j j 1 k 2}, \quad \frac{a_{k} C_{k j}+2 a_{j k} C_{k k}}{2 I_{k} \pi^{4}} \bar{\beta}=\beta_{k k 2 j 1}, \quad \frac{a_{j} c_{k k}+2 a_{j k} C_{k j}}{2 I_{k} \pi^{4}} \bar{\beta}=\beta_{k k 1, j 2} \\
& \frac{a_{k} C_{j k}}{2 I_{j} \pi^{4}} \bar{\beta}=\beta_{j k 3}, \quad \frac{a_{k} C_{k k}}{2 I_{k} \pi^{4}} \bar{\beta}=\beta_{k k 3}, \quad \frac{a_{j} c_{k j}}{2 I_{k} \pi^{4}} \bar{\beta}=\beta_{k j 3}, \quad \frac{1}{I_{j}} \bar{\zeta}_{0} W_{j}(0) W_{j}(0)=\zeta_{0 j j}, \quad \frac{1}{I_{j}} \bar{\zeta}_{0} W_{j}(0) W_{k}(0)=\zeta_{0 j k} \\
& \frac{1}{I_{j}} \bar{\zeta}_{1} W_{j}(1) W_{j}(1)=\zeta_{1 j j}, \quad \frac{1}{I_{k}} \bar{\zeta}_{0} W_{k}(0) W_{j}(0)=\zeta_{0 k j}, \quad \frac{1}{I_{k}} \bar{\zeta}_{0} W_{k}(0) W_{k}(0)=\zeta_{0 k k}, \quad \frac{1}{I_{k}} \bar{\zeta}_{1} W_{k}(1) W_{k}(1)=\zeta_{1 k k} \\
& \bar{Q}_{j}=Q_{j}, \quad \bar{Q}_{c j}=Q_{c j}, \quad \bar{Q}_{k}=Q_{k}, \quad \bar{Q}_{c k}=Q_{c k}
\end{aligned}
$$

である. 式(18)を摂動法で解くため正の微小パラメー夕 $\varepsilon$ を導入する.この式の右辺において, 外力パラメータ $Q_{j}, Q_{c j}, Q_{c k}, Q_{k}$ のうち $Q_{k}$ は式(17)を考慮して $O\left(\varepsilon^{1}\right)$ の大きさとし，あとは $O\left(\varepsilon^{0}\right)$ の大きさとする.またこれら以 外のパラメー夕は $O\left(\varepsilon^{1}\right)$ の大きさであるとして, この式を

$$
\begin{aligned}
& \ddot{X}_{j}+p_{j}^{2} X_{j}=\varepsilon\left[\beta_{j j 3} X_{j}^{3}+\beta_{j j 2 k 1} X_{j}^{2} X_{k}+\beta_{j j 1 k 2} X_{k}^{2} X_{j}+\beta_{j k x} X_{k}^{3}-2\left(\zeta+\zeta_{0 j j}+\zeta_{1 j j}\right) \dot{X}_{j}-2\left(\zeta_{0 j k}+\zeta_{1 j k}\right) \dot{X}_{k}\right] \\
& +Q_{c j}+Q_{j} \cos \Omega t \\
& \ddot{X}_{k}+p_{k}^{2} X_{k}=\varepsilon\left[\beta_{k k 3} X_{k}^{3}+\beta_{k k 2 j 1} X_{k}^{2} X_{j}+\beta_{k k 1 j 2} X_{j}^{2} X_{k}+\beta_{k j 3} X_{j}^{3}-2\left(\zeta+\zeta_{0 k k}+\zeta_{1 k k}\right) \dot{X}_{k}-2\left(\zeta_{0 k j}+\zeta_{1 k j}\right) \dot{X}_{j}\right. \\
& \left.+Q_{k} \cos \Omega t\right]+Q_{c k}
\end{aligned}
$$

と書き直す.

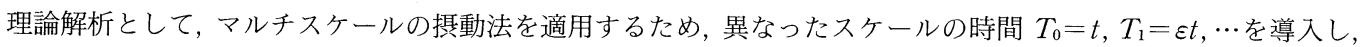
式(20)の末知関数 $X_{j}, X_{k}$ を

$$
X_{s}=X_{s 0}\left(T_{0}, T_{1}, \cdots\right)+\varepsilon X_{s 1}\left(T_{0}, T_{1}, \cdots\right)+\cdots \quad(s=j, k)
$$

の形に扔く。式(21) を式(20)に代入し，摂動法によって $X_{j 0}, X_{k 0}$ が

$$
X_{j 0}=A_{j} e^{i p_{j} T_{0}}+\bar{A}_{j} e^{-i p_{j} T_{0}}+P_{j} e^{i S T_{0}}+P_{j} e^{-i \Omega T_{0}}+D_{c j}, \quad X_{k 0}=A_{k} e^{i p_{k} T_{0}}+\bar{A}_{k} e^{-i p_{k} T_{0}}+D_{c k}
$$

の形に定められる.ここに 


$$
P_{j}=\frac{Q_{j}}{2\left(p_{j}^{2}-\Omega^{2}\right)}, \quad D_{c j}=\frac{Q_{c j}}{p_{j}^{2}}, \quad D_{c k}=\frac{Q_{c k}}{p_{k}^{2}}
$$

は既知の量であり, $A_{j}, A_{k}$ は $T_{1}$ の未知関数, $\overline{A_{j}}, \overline{A_{k}}$ はそれらの共役複素数である.

共振条件式(15)および内部共振条件式(16)を摄動法による解析のために

$$
\Omega=l p_{j}+\varepsilon \sigma_{j}, \quad l p_{j}=p_{k}+\varepsilon \sigma_{k}
$$

とおく.さらに

$$
\sigma_{j h}=\sigma_{j}+\sigma_{k}
$$

とおくと, 式(24)，(25)より

$$
\Omega=p_{k}+\varepsilon \sigma_{j k}
$$

の条件式を得る。ここで $\sigma_{j}, \sigma_{k}, \sigma_{j k}$ は離調パラメータである。

末知関数 $A_{j}, A_{k}$ は, 式(24)，(25)，(26)を考慮して $X_{j 1}, X_{k 1}$ に永年項が生じないための条件

$$
-2 i p_{j} A_{j}^{\prime}-2 i p_{j}\left(\zeta+\zeta_{0 j j}+\zeta_{1 j j}\right) A_{j}+\cdots \cdots \cdots=0, \quad-2 i p_{k} A_{k}^{\prime}-2 i p_{k}\left(\zeta+\zeta_{0 k k}+\zeta_{1 k k}\right) A_{k}+\frac{1}{2} Q_{k} e^{i \sigma_{j k} T_{1}}+\cdots \cdots \cdots=0
$$

によって定められる．ここに肩の記号「'」は $T_{1}$ に関する微分を表す。

末知関数 $A_{j}, A_{k}$ を

$$
A_{j}=\frac{1}{2} R_{j} e^{i\left(\left(\sigma_{j} / l\right) T_{1}+\alpha_{j}\right]}, \quad A_{k}=\frac{1}{2} R_{k} e^{i\left(\sigma_{j k} T_{1}+\alpha_{k}\right)}
$$

とおいて式(27) に代入し実部と虚部を分離して $R_{j}, \alpha_{j}, R_{k}, \alpha_{k}$ を未知数とする実係数の方程式を求める.

上述のようにして得られる実係数の方程式の定常解は, 条件

$$
R_{j}^{\prime}=0, \quad \alpha_{j}^{\prime}=0, \quad R_{k}^{\prime}=0, \quad \alpha_{k}^{\prime}=0 .
$$

によって求められる。

定常振動の安定性は, 定常解に対応する $A_{j}, A_{k}$ に微小な乱机を与え, その時間的変化を調べることによって定 められる。このため, 式(27)の $A_{j}, A_{k}$ にそれぞれ $A_{j}+\Delta_{j}, A_{k}+\Delta_{k}$ を代入し, $\Delta_{j}, \Delta_{k}$ の 2 乗以上微小量を無視して $\Delta_{j}, \Delta_{k}$ を支配する方程式を求める。この式の $\Delta_{j}, \Delta_{k}, A_{j}, A_{k}$ をそれぞれ

$$
\Delta_{j}=\left(\xi_{j}+i \eta_{j}\right) e^{i(1 / l) \sigma_{j} T_{1}}, \quad \Delta_{k}=\left(\xi_{k}+i \eta_{k}\right) e^{i \sigma_{j k} T_{1}}, \quad A_{j}=\frac{1}{2}\left(U_{j}+i V_{j}\right) e^{i(1 / l) \sigma_{j} T_{1}}, \quad A_{k}=\left(U_{k}+i V_{k}\right) e^{i \sigma_{j k} T_{1}}
$$

とおき, $\Delta_{j}, \Delta_{k}$ を支配する方程式を実部と虚部に分離して $\xi_{j}, \eta_{j}, \xi_{k}, \eta_{k}$ に関する方程式を求めると

$$
\begin{array}{ll}
\xi_{j}^{\prime}=A_{11} \xi_{j}+A_{12} \eta_{j}+A_{13} \xi_{k}+A_{14} \eta_{k}, & \eta_{j}^{\prime}=A_{21} \xi_{j}+A_{22} \eta_{j}+A_{23} \xi_{k}+A_{24} \eta_{k} \\
\xi_{k}^{\prime}=A_{31} \xi_{j}+A_{32} \eta_{j}+A_{33} \xi_{k}+A_{34} \eta_{k}, & \eta_{k}^{\prime}=A_{41} \xi_{j}+A_{42} \eta_{j}+A_{43} \xi_{k}+A_{44} \eta_{k}
\end{array}
$$

の形の式を得る. 式(31)の特性方程式に Routh-Hurwitz の判別法を適用する.

$3 \cdot 2 \quad 1 / 3$ 次分数調波振動の発生 最初に, 式 $(24)$ の $l$ を $l=3$ とおいて発生が可能な $1 / 3$ 次分数調波振動を取 り上げる.このためこの場合の式(27) 導く.この式で, 未知関数 $A_{j}$ を式(28)で $l=3$ とした形におき,さらに実 部と虚部に分離すると

$$
\begin{aligned}
& p_{j} R_{j}^{\prime}=-p_{j}\left(\zeta+\zeta_{0 j}+\zeta_{1 j}\right) R_{j}-\frac{3}{4} \beta_{j j 3} P_{j} R_{j}^{2} \sin 3 \alpha_{j}+\frac{1}{8} \beta_{j j 2 k 1} R_{k} R_{j}^{2} \sin \left(\alpha_{k}-3 \alpha_{j}\right) \\
& p_{j} R_{j} \alpha_{j}^{\prime}=-\frac{1}{3} p_{j} \sigma_{j} R_{j}-\beta_{j j 3}\left(3 P_{j}^{2} R_{j}+D_{c j}^{2}\right) R_{j}-\beta_{j j 2 k 1} D_{c j} D_{c k} R_{j}-\beta_{j j 1 k 2}\left(\frac{1}{4} R_{j} R_{k}^{2}+\frac{1}{2} D_{c k}^{2} R_{j}\right) \\
& \quad-\frac{3}{8} \beta_{j j 3} R_{j}^{3}-\frac{3}{4} \beta_{j j 3} P_{j} R_{j}^{2} \cos 3 \alpha_{j}-\frac{1}{8} \beta_{j j 2 k 1} R_{k} R_{j}^{2} \cos \left(\alpha_{k}-3 \alpha_{j}\right)-\beta_{j j 2 k 1} P_{j} R_{j} R_{k} \cos \alpha_{k} \\
& p_{k} R_{k}^{\prime}=-p_{k}\left(\zeta+\zeta_{0 k k}+\zeta_{1 k k}\right) R_{k}-\beta_{k k 1 j 2} P_{j}^{2} R_{k} \sin 2 \alpha_{k}-\frac{1}{2} \beta_{k j 3} R_{j}^{3} \sin \left(\alpha_{k}-3 \alpha_{j}\right)+\left[\beta_{k k 2 j 1}\left(\frac{1}{2} P_{j} R_{k}^{2}+D_{c k}^{2}\right)\right. \\
& \left.\quad+\beta_{k j 3}\left(3 P_{j}^{3}+\frac{3}{2} P_{j} R_{j}^{2}+3 D_{c j}^{2} P_{j}\right)+2 \beta_{k k 1 j 2} D_{c j}+D_{c k} P_{j}+\frac{1}{2} Q_{k}\right] \sin \alpha_{k}-2 p_{j} \Omega\left(\zeta_{0 k j}+\zeta_{1 k j}\right) \cos \alpha_{k} \\
& p_{k} R_{k} \alpha_{k}^{\prime}=-p_{k} \sigma_{j k} R_{k}+\beta_{k k 2 j 1} D_{c j} D_{c k} R_{k}-\frac{1}{2} \beta_{k k 1 j 2}\left(\frac{1}{2} R_{j}^{2}+2 P_{j}^{2}+D_{c j}^{2}\right) R_{k}-\beta_{k k 3}\left(\frac{3}{8} R_{k}^{3}+\frac{3}{2} D_{c k}^{2} R_{k}\right) \\
& \quad-\beta_{k k 1 j 2} P_{j}^{2} R_{k} \cos 2 \alpha_{k}-\frac{1}{2} \beta_{k j 3} R_{j}^{3} \cos \left(\alpha_{k}-3 \alpha_{j}\right)+\left[\beta_{k k 2 j 1}\left(\frac{1}{2} P_{j} R_{k}^{2}+D_{c k}^{2}\right)\right.
\end{aligned}
$$


を得る。

式 (32)の定常解は条件 (29)によって求められる. 定常解 $R_{j}, \alpha_{j}, R_{k}, \alpha_{k}$ が求まれば, たわみ $w$ はこれらを式 (28), (22)，(21)，（７）に順次代入すれば

$$
w=\left[R_{j} \cos \left(p_{j} t+\alpha_{j}+\frac{1}{3} \varepsilon \sigma_{j} t\right)+2 P_{j} \cos \Omega t+D_{c j}\right] W_{j}(x)+\left[R_{k} \cos \left(\Omega t+\alpha_{k}\right)+D_{c k}\right] W_{k}(x)
$$

の形で与えられる. 後の数值例で示されるように, 条件 (29)によって定められる式(32)の定常解には

$$
\text { (a) } R_{j}=0, \quad R_{k} \neq 0, \quad \text { (b) } R_{j} \neq 0, \quad R_{k} \neq 0
$$

となる 2 種類が存在する．（a）は調和振動のみの発生を意味する（（b) は調和振動以外に $R_{j}$ を振幅とする定常振 動を含み得ることがわかる。この振動成分の角振動数を $\omega_{j}$ とおくと

$$
\omega_{j}=p_{j}+\alpha_{j}^{\prime}+\frac{1}{3} \varepsilon \sigma_{j}
$$

である。式(35)に式(29)および式(24)を代入すると

$$
\omega_{j}=\frac{1}{3} \Omega
$$

を得る。したがって，この場合のたわみ $w$ の振動は, $R_{j}$ を振幅とする $1 / 3$ 次分数調波振動と $R_{k}$ を振幅とする $k$ 次調和振動成分の多モード形で発生することがわかる.

$3 \cdot 3 \quad 1 / 2$ 次分数調波振動 次に, 式(24)の $l$ を $l=2$ とおいて発生が可能な $1 / 2$ 次分数調波振動を取り上げる. このためこの場合の式 (27) を導く。この式で, 未知関数 $A_{j}$ を式(28)で $l=2$ とした形におき,さらに実部と虚部に 分離すると

$$
\begin{aligned}
& p_{j} R_{j}^{\prime}=-p_{j}\left(\zeta+\zeta_{0 j j}+\zeta_{1, j}\right) R_{j}+\frac{1}{2} \beta_{j j 2 k 1} D_{c j} R_{j} R_{k} \sin \left(-2 \alpha_{j}+a_{k}\right) \\
& p_{j} R_{j} \alpha_{j}^{\prime}=-\frac{3}{8} \beta_{j j 3} R_{j}^{3}+\left[-\frac{1}{2} p_{j} \sigma_{j}-\beta_{j j 3}\left(3 P_{j}^{2}+3 P_{j} D_{c j}+\frac{3}{2} D_{c j}^{2}\right)-\beta_{j j 2 k 1} D_{c k}\left(D_{c j}+P_{j}\right)\right. \\
& \left.-\frac{1}{2} \beta_{j j 1 k 2} D_{c k}^{2}\right] R_{j}-\frac{1}{4} \beta_{j j 1 k 2} R_{j} R_{k}^{2}-\beta_{j j 2 k 1} P_{j} R_{j} R_{k} \cos \alpha_{k}-\frac{1}{2} \beta_{j j 2 k 1} D_{c j} R_{j} R_{k} \cos \left(-2 \alpha_{j}+\alpha_{k}\right) \\
& p_{k} R_{k}^{\prime}=-p_{k}\left(\zeta+\zeta_{0 k k}+\zeta_{1 k k}\right) R_{k}+\left[-\beta_{k k 2 j 1} P_{j} D_{c k}^{2}-2 \beta_{k k 1 j 2} P_{j} D_{c j} D_{c k}\right. \\
& \left.+\beta_{k j 3}\left(-3 P_{j}^{3}-3 D_{c j}^{2} P_{j}\right)\right] \sin \alpha_{k}-\frac{1}{4} \beta_{k k 2 j 1} P_{j} R_{k}^{2} \sin \alpha_{k}+\left(\frac{1}{4} \beta_{k k 1 j 2} D_{c k}-\frac{3}{2} \beta_{k j 3} P_{j}\right) R_{j}^{2} \sin \alpha_{k} \\
& -\frac{1}{2} \beta_{k k 1 j 2} D_{c j}^{2} R_{k} \sin \alpha_{k}-2\left(\zeta_{0 k j}+\zeta_{1 k j}\right) \Omega P_{j} \cos \alpha_{k}-\frac{1}{2} \beta_{k k 1 j 2} P_{j}^{2} R_{k} \sin 2 \alpha_{k}+\frac{3}{4} \beta_{k j 3} D_{c j} R_{j}^{2} \sin \left(2 \alpha_{j}-\alpha_{k}\right) \\
& p_{k} R_{k} \alpha_{k}^{\prime}=-\frac{3}{8} \beta_{k k 3} R_{k}^{3}+\left(-p_{k} \sigma_{j k}-\frac{3}{2} \beta_{k k 3} D_{c k}^{2}-\beta_{k k 2 j 1} D_{c j} D_{c k}+\beta_{k k 1 j 2} P_{j}^{2}\right) R_{k}+\frac{1}{4} \beta_{k k 1 j 2} R_{j}^{2} R_{k} \\
& -\left[\beta_{k k 2 j 1} P_{j} D_{c k}^{2}+2 \beta_{k k 1 j 2} P_{j} D_{c j} D_{c k}+3 \beta_{k j 3}\left(P_{j}^{3}+D_{c j}^{2} P_{j}\right)\right] \cos \alpha_{k}+\frac{3}{4} \beta_{k k 2 j 1} P_{j} R_{k}^{2} \cos \alpha_{k}+\frac{1}{2} \beta_{k k 1 j 2} D_{c j}^{2} R_{k} \cos \alpha_{k} \\
& +\left(\frac{1}{4} \beta_{k k 1 j 2} D_{c k}+\frac{3}{2} \beta_{k j 3} P_{j}\right) R_{j}^{2} \cos \alpha_{k}-2\left(\zeta_{0 k j}+\zeta_{1 k j}\right) \Omega P_{j} \sin \alpha_{k}-\frac{1}{2} \beta_{k k 1 j 2} P_{j}^{2} R_{k} \cos 2 \alpha_{k} \\
& -\frac{3}{4} \beta_{k j 3} D_{c j} R_{j}^{2} \cos \left(2 \alpha_{j}-\alpha_{k}\right)
\end{aligned}
$$

を得る。

式(37)の定常解は，条件(29)によって求められる，定常解が求まればたわみ $w$ はこれらを式(28)，(22)，(21)， （7）に順次代入すれば

$$
w=\left[R_{j} \cos \left(p_{j} t+\alpha_{j}+\frac{1}{2} \varepsilon \sigma_{j} t\right)+2 P_{j} \cos \Omega t+D_{c j}\right] W_{j}(x)+\left[R_{k} \cos \left(\Omega t+\alpha_{k}\right)+D_{c k}\right] W_{k}(x)
$$

の形で与えられる. 後の数值例に示されるように, 条 件 (29)によって定められる式(37)の定常解には，ここ でも式(34)で与えられる 2 種類が存在する. 式 (34)の ( b ) の $R_{j}$ を振幅とする定常振動の角振動数を $\omega_{j}$ と おくとここでは

$$
\omega_{j}=\frac{1}{2} \Omega
$$

を得る.したがって，この場合のたわみ $w$ の振動は， $R_{j}$ を振幅とする $1 / 2$ 次分数調波振動と $R_{k}$ を振幅と する $k$ 次調和振動成分の多モード形で発生すること 
がわかる.ただし, この分数調波振動が発生するため には，式(37)の第 1 式からわかるように, $D_{c j} \neq 0$ すな わち外力のうち時間に依存しない成分が 0 とならない 条件が必要となる。

\section{4. 数 值 例}

数值例によって, 分数調波振動が発生することを確 認し，その振動特性を検討する.

固有角振動数は, 式(10)からわかるように, 両端支 持ばねのばね定数パラメータ $k_{0}$ および $k_{1}$ に依存す る.ここでは実際上重要な第 1,2 次固有角振動数 $p_{1}$ および $p_{2}$ を取り上げ，ばね定数值がこれらに及ぼす 影響を調べた結果, 2 個のばね定数の值によっては異 なる 2 つの固有角振動数 $p_{1}$ および $p_{2}$ の間に内部共振 の関係が成立し得ることを見出した，具体的には両端 支持ばねの剛性を等しく置いた場合 $\left(k_{0}=k_{1}=K\right)$ につ いて調べる。まず最初に, $1 / 3$ 次分数調波振動が発生 する系が内部共振系を形成し得るか否かを見るため, 横軸に $K$ をとり, 縦軸に $3 p_{1}, p_{2}$ をとった関係を図 1 に示す. 図から, 内部共振 $3 p_{1} \cong p_{2}$ を満たすばね定数 值がグラフの交点付近に存在することがわかる.ここ では $k_{0}=k_{1}=200$ とおいて $1 / 3$ 次分数調波振動の振動 特性を以下に示す. 適当なパラメータでの数值例を共 振曲線の形で図 2 に示す。図中, 横軸に調和外力の角

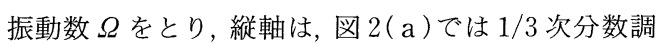
波振動の振幅 $R_{1}$, 第 1 次モード形の調和成分の振幅 $2 P_{1}$ をとり,図 $2(\mathrm{~b})$ では第 2 次モード形の調和振動 の振幅 $R_{2}$ をとる。これらの図中の曲線は, 式(32)の 定常解 ( a ) に対応する $R_{1}=0$ のときの分枝 $\mathrm{AB}, \mathrm{CD}$ と, 定常解 ( $\mathrm{b}$ ) に対応する $R_{1} \neq 0$ のときの分枝 $\mathrm{EF}$, EGから成る。いずれの図においても, 実線は安定, 破線は不安定な振動を示す。

図 2 に抢いて, 調和外力の角振動数 $\Omega$ を小さい值 加ら増加させると, 分枝 $\mathrm{AB}$ に沿って $R_{2}$ を振幅とす る調和振動が第 2 次モード形の単一モード形で発生す

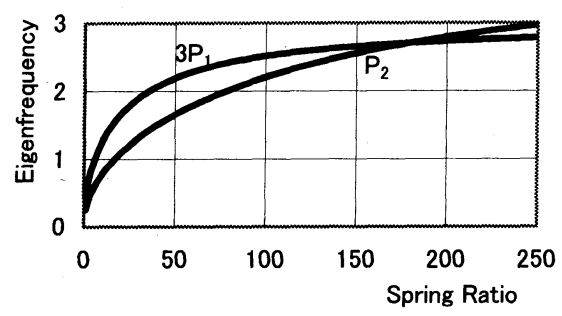

Fig. 1 Influence of spring constants on eigenfrequencies $\left(k_{0}=k_{1}=K\right)$
る. E に対応する振動数を越えると, 分枝 $\mathrm{CD}$ の実線 部分抢よび $\mathrm{EF}$ が安定な分枝であるので, 適当な初期 条件を与えると, これらの分枝のいずれかに移行し得 る. 第 2 次モード形の単一モード形で移行する場合は 分枝 $\mathrm{CD}$ に跳躍する. 一方, 分枝 $\mathrm{EF}$ に移行する場合 には, 同時に $R_{1}$ を振幅とする $1 / 3$ 次分数調波振動が 第 1 次モード形で発生し多モード形となる.

モード方程式(13)を $n=1,2$ について直接数值積分 して応答振動波形を求め, 更にこの波形をフーリエス ペクトルに分解した. 図中，○，○，ロはこのスペク トル分解の結果より得られた振幅を示す。これらより 近似理論解析の妥当性を確認した。

次に, $1 / 2$ 次分数調波振動が発生する系が内部共振 系を形成し得るか否かを見るため, 前と同様に横軸に $K$ をとる，ここでは縦軸に $2 p_{1}, p_{2}$ をとった関係を図

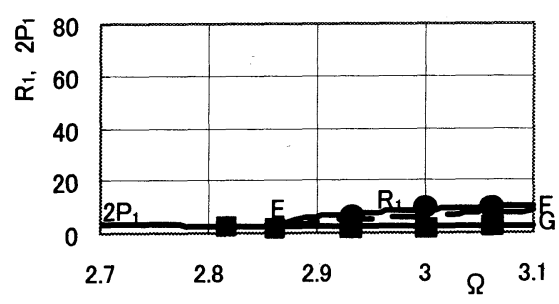

(a) First mode

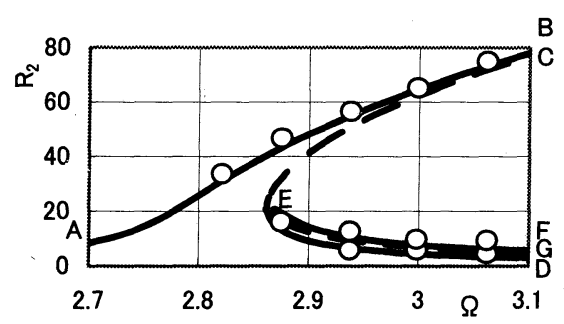

(b) The second mode

Fig. 2 Resonance curves $\left(\varepsilon=0.1, \bar{\beta}=0.001, Q_{1}=20, Q_{2}\right.$ $\left.=50, Q_{c 1}=Q_{c 2}=0, \bar{\zeta}=0.1, \bar{\zeta}_{0}=\bar{\zeta}_{1}=0.01\right)$

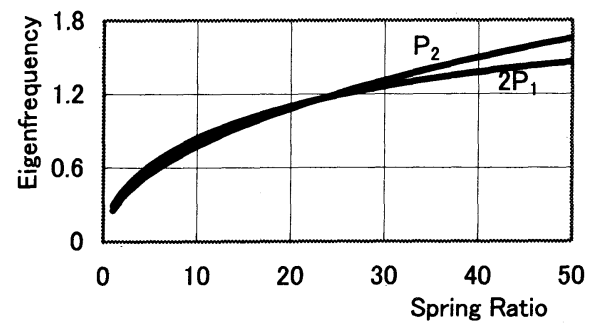

Fig. 3 Influence of spring constants on eigenfrequencies $\left(k_{0}=k_{1}=K\right)$ 


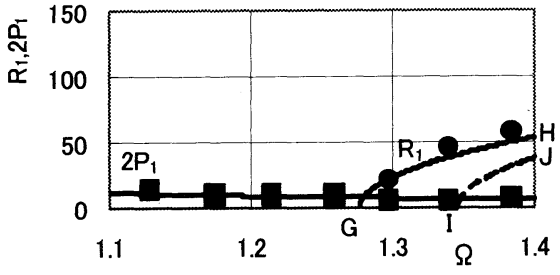

(a) First mode

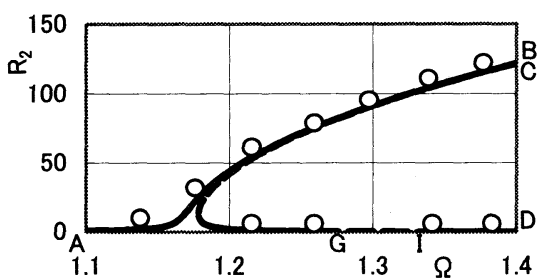

(b) Second mode

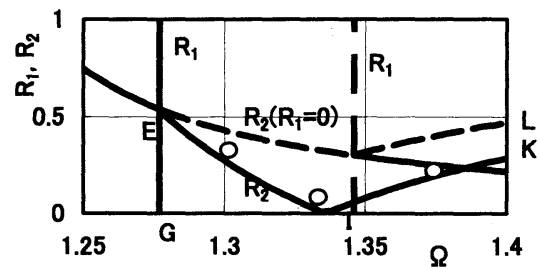

(c) Details of bifurcation point neighborhood

Fig. 4 Resonance curves $\left(\varepsilon=0.1, \bar{\beta}=0.001, Q_{1}=10, Q_{2}\right.$ $\left.=10, Q_{c 1}=10, Q_{c 2}=10, \bar{\zeta}=\bar{\zeta}_{0}=\bar{\zeta}_{1}=0.01\right)$

3 に示す. 図から, 内部共振 $2 p_{1} \cong p_{2}$ を満たすばね定 数值が存在することがわかる. $k_{0}=k_{1}=23$ とおいて $1 / 2$ 次分数調波振動の数值例を共振曲線の形で図 4 に 示す. 図中, 横軸は前と同様にとり, 縦軸には, 図 4 (a) に扔いては $1 / 2$ 次分数調波振動の振幅 $R_{1}$, 第 1 次モード形の調和成分の振幅 $2 P_{1}$ を, 図 $4(\mathrm{~b})$ では第 2 次モード形の調和振動の振幅 $R_{2}$ を, 部分詳細図で ある図 4( c ) では $R_{1}, R_{2}$ をとる。これらの図中の曲 線は, 式 (32)の定常解 ( a ) に対応する $R_{1}=0$ のときの 分枝 $\mathrm{AB}, \mathrm{CD}$ と $2 P_{1}$ で示される第 1 次モードの調和 振動の振幅と, 定常解 ( $\mathrm{b}$ ) に対応する $R_{1} \neq 0$ のときの 分枝 GH, IJ を示す。実線，破線の意味は前と同様で ある。

図 4 において, 調和外力の角振動数 $\Omega$ を小さい值 から増加させると, 分枝 $\mathrm{AB}$ に沿って $R_{2}$ を振幅とす る調和振動が第 2 次モード形の単一モード形で発生す る. 振動数が安定不安定の分岐点を越え, Gで示され
る点に対応する振動数までの間では適当な初期条件を 与えると分枝 CD の安定部に跳躍移行し得る。移行し た後は, 図 4 (c) で示されるように Gで示される点に 対応する振動数を越えると分枝 $\mathrm{EK} に$ 連続的に分岐 し，同時に分枝 $\mathrm{GH}$ で表される $R_{1}$ を振幅とする $1 / 2$ 次分数調波振動が第 1 次モード形で発生し多モード形 となる。

図中, $， \bigcirc ， \boldsymbol{口}$ は, 前と同様フーリエスペクトル分 解の結果を示す。これらより近似理論解析の妥当性を 確認した.

\section{5. まと め}

両端をばねと減衰器で支持したはりに調和外力と時 間に依存しない外力が作用するときに発生が可能であ る分数調波振動の問題を理論と数值シミュレーション より検討し, 以下の結論を得た。

（1）両端の支持ばねのばね定数の值によって，系 は内部共振系になり得る。

（2） 2 つの固有角振動数の比が 3 倍となる内部共 振系には, 調和振動と $1 / 3$ 次分数調波振動が多モード で発生し得る。

（3） 2 つの固有角振動数の比が 2 倍となる内部共 振系には, 調和振動と $1 / 2$ 次分数調波振動が多モード 形で発生し得る。

（4） $1 / 2$ 次分数調波振動が発生するためには，時 間に依存しない外力が必要となる。

（5）理論解析の結果を数值シミュレーション結果 と比較することによりその妥当性を確認した。

\section{文献}

(1) Kato, M., Yasuda, K. and Nishiuchi, H., Combination tones in a Beam Subjected to Nonsymmetric External Forces (in Japanese), Transactions of the Japan Society of Mechanical Engineers, Series C, Vol. 69, No. 678 (2003), pp. 24-31.

(2) Öz, H. R., Pakdemirli, M., Özkaya, E. and Yilmaz, M., Non-linear Vibrations of a Slightly Curved Beam Resting on Non-linear Elastic Foundation, Journal of Sound and Vibration, Vol. 212 ( 2 ) (1998), pp. 295-309.

(3) Nayfeh, A. H. and Mook, D. T., Nonlinear Oscillations, (1979), p. 465, John Wiley \& Sons.

(4) Yamamoto, T., Yasuda, K. and Aoki, K., Subharmonic Oscillations of a Slender Beam (in Japanese), Transactions of the Japan Society of Mechanical Engineers, Series C, Vol. 46, No. 410 (1980), pp. 1171-1179.

(5) Yasuda, K. and Hayashi, N., Subharmonic Oscillations of a Prestressed Circular Plate (in Japanese), Transac tions of the Japan Society of Mechanical Engineers, Series C, Vol. 47, No. 420 (1981), pp. 987-999. 